\title{
FREQUENCY OF H. PYLORI INFECTION IN CHILDREN WITH RECURRENT ABDOMINAL PAIN AT A TERTIARY CARE HOSPITAL.
}

\footnotetext{
1. MBBS, FCPS (Pediatrics Medicine) Associate Professor Pediatrics $\mathrm{CHC} \& \mathrm{ICH}$ Multan Pakistan.

2. MBBS, FCPS (Pediatrics Medicine) Senior Registrar Pediatrics Medicine $\mathrm{CHC} \& \mathrm{ICH}$, Multan.

3. MBBS

Post Graduate Trainee Pediatrics Nishtar Hospital, Multan.
}

Correspondence Address: Dr. Asim Khurshid

Associate Professor Pediatrics $\mathrm{CHC} \& \mathrm{ICH}$ Multan Pakistan. asimkhurshiddr@gmail.com

Article received on: 19/01/2019 Accepted for publication: $10 / 05 / 2019$

\section{Asim Khurshid ${ }^{1}$, Shahid Ishaq ${ }^{2}$, Mushtaq Ahmad ${ }^{3}$}

ABSTRACT... Objectives: Recurrent abdominal pain (RAP) impacts quality of life of the children. RAP also hampers education and physical activity of the children. Current study was aimed to find out the frequency of Helicobacter pylori in children with RAP in our tertiary care hospital. Study Design: Descriptive, cross-sectional study. Setting: Department of Pediatric Medicine, Nishtar Hospital, Multan, Period: From 27-12-2017 to 26-06-2018. Material \& Methods: A total of 185 patients suffering from RAP, aged 2-12 years, with a disease duration $>3$ months, were enrolled. Age of the children, gender, duration of illness, number of episodes of pain, maternal literacy, family income, residential status, source of drinking water and h.pylori infection were calculated in these children. Post stratification chi-square test was applied to see its effect on H. Pylori infection. Results: Of these 185 study cases, 101 (54.6\%) were male patients while $84(45.4 \%)$ were female. Mean age of our study cases was $7.57 \pm 1.93$ years. Of A total of 95 $(51.4 \%)$ children belonged to rural areas and 90 (48.6 \%) to urban areas. Helicobacter pylori infection was noted in $103(55.7 \%)$ of our study cases. When helicobacter pylori was stratified with regards to study variables, male gender, age $\leq 8$ years, monthly family income $\leq$ Rs. 35000 , source of drinking water as Hand Pump and disease duration $\leq 6$ months turned out to be statistically significant $(P$ value $\leq 0.05)$. Conclusion: Frequency of H.pylori was high in children with RAP. Helicobacter pylori was significantly associated with male gender, younger age, poor socioeconomic status, source of drinking water and disease duration.

Key words: $\quad$ Frequency, H. Pylori, Recurrent Abdominal Pain.

Article Citation: Khurshid A, Ishaq S, Ahmad M. Frequency of H. Pylori infection in children with recurrent abdominal pain at a Tertiary Care Hospital. Professional Med J 2020; 27(2):237-241. DOI: 10.29309/TPMJ/2020.27.2.3057

\section{INTRODUCTION}

More than $50 \%$ of the global population is said to have H.pylori. H.pylori mostly affects children $<5$ years of age. ${ }^{1}$

Prevalence rates of $1-12 \%$ are found in developed countries..$^{2,3}$

Much higher occurrence of H.pyloriis found in developing countries. In Gambia, 15\% children < 2 years of age had serological prevalence rates of $\mathrm{H}$.pylori while $46 \%$ aged $3-5$ years. In India, $45 \%$ whereas in Bolivia and Alaska, about $70 \%$ were found to have seroloprevalence of h.pylori. ${ }^{4,5}$

Low socioeconomic status is the commonest predisposing factor related to h. pylori. ${ }^{6}$ Association of h.pylori and RAP has been researched keenly in the last few years. Dissimilarity in outcomeshas come out due to different study designs. Difference in methodologies led to controversies in the outcomes related to association of h.pylori and RAP. A meta-analysis of 45 studies noted a weak and incoherentevidence of the linkage between H.pylori infection and RAP. ${ }^{7}$

Routine testing of $\mathrm{H}$.pylori in pediatric population having RAP is not advised by renowned paediatric global bodies. 8,9

In Islamabad, Hafez et $\mathrm{al}^{10}$ found frequency of $\mathrm{H}$. Pylori infection as $75 \%$ in pediatric population withRAP. Mahmud et $\mathrm{al}^{11}$ in another study got $38 \%$ H.pylori infection while in Iran, Ali mohammadi et al $^{12}$ noted $58 \%$ H.pylori infection in children with RAP.

This study is proposed to document the frequency 
of $\mathrm{H}$. pylori in children with RAP, as there is much variation among reported proportions ranging from38 \% to $75 \% .^{10-12}$ These results are aimed to generate useful database of our population that will be comparable to many others from various parts of the globe. We wanted to find out the frequency of $\mathrm{H}$.pylori in children with RAP in our tertiary care hospital.

\section{MATERIAL AND METHODS}

This was a descriptive, cross-sectional study, conducted at The Department of Pediatric Medicine, Nishtar Hospital, Multan, from 27-122017 to 26-06-2018. A total of 185 patients having RAP (It was deemed as positive in case of at least 3 discrete episodes of abdominal pain lasting for more than 1 hour over a period of more than 3 months which affects partially physical activity and schooling), aged 2-12 years, both boys and girls, with a disease duration more than 3 months, wereconsidered for this study employing nonprobability consecutive sampling technique. All patients already using antibiotics, bismuth and PPIs (confirmed from patient record file), having pancreatitis, acute cholecystitis or intestinal obstruction (confirmed from patient record file) or whose parents didn't give consent of participation were barred from the study.

Source of patients was Pediatric OPD of Nishar Hospital, Multan. Proper permission was takenfrom Institutional Ethical Committee to conduct this study. Informed consent was taken from the parents of these children describing them objectives of this study,ensuring them confidentiality of the information provided and fact that there wasno risk involved to the patient while taking part in this study. Fresh stool samples of each child were sent to the Pathology laboratory of Nishtar Hospital for H.pylori stool antigen testing. Specimen was examined by a senior pathologist with 15 years working experience in Pathology department.

Descriptive statistics was applied to calculate mean and standard deviation for the age, duration of illness and number of episodes of pain. Frequencies and percentage were tabulated for the categorical variables like age groups, maternal literacy, familyincome, residential status, source of drinking water, gender, $\mathrm{H}$. Pylori infection. Effect modifiers like age, duration of illness, maternal literacy, monthly family income, residential status, source of drinking water, Number of episodes and genderwas controlled by making stratified tables. Post stratification chi-square test wasapplied to see its effect on $\mathrm{H}$. Pylori infection. $\mathrm{P}$ value $\leq 0.05$ was considered as significant.

\section{RESULTS}

Of the 185 study cases, 101 (54.6\%) were male while 84 (45.4\%) were female patients. Mean age of our study cases was $7.57 \pm 1.93$ years (with minimum age of our study cases was 3 years while maximum age was 12 years). Mean age of the male patients was noted to be $7.91 \pm 2.03$ years while that female patients was $7.15 \pm 1.71$ years $(p=0.008)$. Our study results have indicated that majority of our study cases i.e. 128 (69.2\%) were aged $\leq 8$ years.

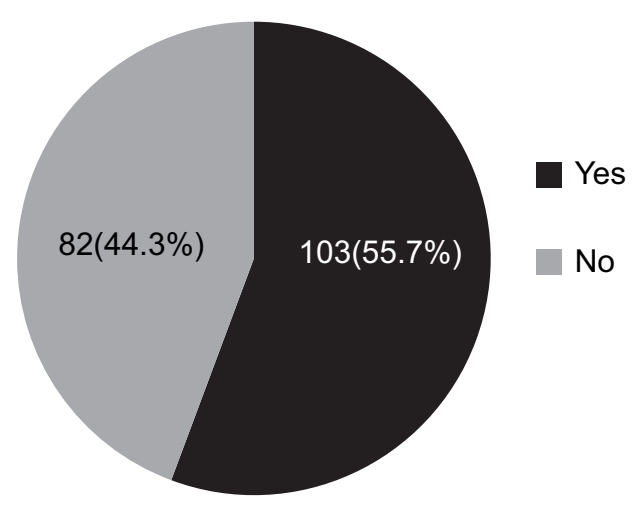

Figure-1. Distribution of Helicobacter pylori infection among study cases $(n=185)$

Of these 185 study cases, 95 (51.4\%) belonged to rural areas and 90 (48.6\%) belonged to urban areas. Monthly family income up to Rs. 35000 was noted in 129 (69.7\%) and more than Rs. 35000 was noted in 56 (30.3\%) of our study cases. Of these 185 study cases, 134 (72.4\%) mothers were illiterate while 51 (27.6\%) mothers were literate. Of these 185 study cases, 45 (24.3\%) were having water supply as their source for drinking water while 140 (75.7\%) were drinking water from hand pumps. Mean disease duration was $5.16 \pm$ 1.92 months and 141 (76.2\%) of our study cases had duration of illness $\leq 6$ months. Mean no. of 
episodes was $7.12 \pm 2.35$ and 137 (74.1\%) had $>5$ no. of episodes.

Helicobacter pylori infection was noted in 103 $(55.7 \%)$ of our study cases. When helicobacter pylori was stratified with regards to study variables, male gender, age $\leq 8$ years, monthly family income $\leq$ Rs. 35000 , source of drinking water as Hand Pump and disease duration $\leq 6$ months turned out to be statistically significant $(P$ value $\leq 0.05$ ).

\begin{tabular}{|c|c|c|c|}
\hline \multirow[b]{2}{*}{ Study Variables } & \multicolumn{2}{|c|}{ Helicobacter Pylori } & \multirow{2}{*}{$\begin{array}{c}\text { P- } \\
\text { Value }\end{array}$} \\
\hline & $\begin{array}{c}\text { Yes } \\
(n=103)\end{array}$ & $\begin{array}{c}\text { No } \\
(n=82)\end{array}$ & \\
\hline \multicolumn{4}{|l|}{ Gender } \\
\hline Male $(n=101)$ & $69(67.0 \%)$ & $32(39.0 \%)$ & \multirow{2}{*}{$<0.001$} \\
\hline Female $(\mathrm{n}=84)$ & $34(33.0 \%)$ & $50(61.0 \%)$ & \\
\hline \multicolumn{4}{|l|}{ Age } \\
\hline$\leq 8$ Years $(n=128)$ & $62(60.2 \%)$ & $66(80.1 \%)$ & \multirow{2}{*}{0.004} \\
\hline$>8$ Years $(n=57)$ & $41(39.8 \%)$ & $16(19.9 \%)$ & \\
\hline \multicolumn{4}{|l|}{ Residential Status } \\
\hline Rural(n=95) & $57(55.3 \%)$ & $38(46.3 \%)$ & \multirow{2}{*}{0.239} \\
\hline $\operatorname{Urban}(n=90)$ & $46(44.7 \%)$ & $44(53.7 \%)$ & \\
\hline \multicolumn{4}{|c|}{ Monthly Family Income } \\
\hline$\leq$ Rs. $35000(n=129)$ & 93 (90.3\%) & $36(43.9 \%)$ & \multirow{2}{*}{$<0.001$} \\
\hline$>$ Rs. $35000(n=56)$ & $10(9.7 \%)$ & $46(56.1 \%)$ & \\
\hline \multicolumn{4}{|l|}{ Maternal literacy } \\
\hline Illiterate $(n=134)$ & 79 (76.7\%) & $55(67.1 \%)$ & \multirow{2}{*}{0.185} \\
\hline Literate $(n=51)$ & $24(23.3 \%)$ & 27 (32.9\%) & \\
\hline \multicolumn{4}{|l|}{ Water Source } \\
\hline Govt. Supply $(n=45)$ & $18(17.5 \%)$ & 27 (32.9\%) & \multirow{2}{*}{0.017} \\
\hline Hand Pump $(n=140)$ & 85 (82.5\%) & $55(67.1 \%)$ & \\
\hline \multicolumn{4}{|l|}{ Disease Duration } \\
\hline$\leq 6$ months $(n=141)$ & 85 (82.5\%) & $56(68.3 \%)$ & \multirow{2}{*}{0.036} \\
\hline$>6$ months $(n=44)$ & $18(17.5 \%)$ & $26(31.7 \%)$ & \\
\hline \multicolumn{4}{|l|}{ No. of Episodes } \\
\hline$\leq 5(n=48)$ & $26(25.2 \%)$ & $22(26.2 \%)$ & \multirow{2}{*}{0.867} \\
\hline$>5(n=137)$ & 77 (74.8\%) & $60(73.8 \%)$ & \\
\hline
\end{tabular}

\section{DISCUSSION}

H.pylori is a -ve gram stained rod that fabricates urease, catalase, and oxidase that in turn take part in the pathogenesis of peptic ulcer disease. Most likely transmission is through feco-oral route. ${ }^{13}$ In the current study, 101 (54.6\%) were male sand 84 (45.4\%) females. Younas and colleagues ${ }^{14}$ from Peshawar reported male majority with $61 \%$ having recurrent abdominal pain which is similar to current work. A Turkish study ${ }^{15}$ reported $53 \%$ male predominance with RAP. A local study ${ }^{11}$ reported $58 \%$ male gender presenting with RAP. On the contrary, Ali mohammadi and Colleageues ${ }^{12}$ from Iran found a bit higher female predominance.

Overall mean age in the current study was 7.57 \pm 1.93 years (with minimum age of 3 years while maximum age was 12 years). Mean age amongst male children was noted to be $7.91 \pm$ 2.03 years while that female patients was $7.15 \pm$ 1.71 years $(p=0.008)$. Majority of the children, 128 $(69.2 \%)$ were aged $<8$ years. Younas et $\mathrm{al}^{14}$ from Rawalpindi witnessed comparable results where mean age of the study cases with RAP was 86 months. In Turkey ${ }^{15}$, it was found that mean age was 9 years which is close to our study results. Another local study ${ }^{11}$ also found similar findings.

We had 95 (51.4\%) children from rural areas whereas monthly family income of $<$ Rs. 35000 was found in 129 (69.8\%). We noted, 134 (72.4\%) mothers were illiterate and 140 (75.7\%) were drinking water from hand-pumps. In Rawalpindi ${ }^{11}$, $59 \%$ children with RAP belonged to poor families which is similar to our findings. In Iran, Ali mohammadi et $\mathrm{al}^{12}$ also obtained similar findings.

H.pylori infection was noted in 103 (55.7\%) of our study cases. Telmesani et al ${ }^{16}$ from Saudi Arabia found $73 \% \mathrm{H}$. pylori infection in children with RAP which is slightly higher than that what we reported in our study. Zeyreket $\mathrm{al}^{15}$ from Turkey noted $49 \%$ prevalence of $\mathrm{H}$. pylori infection which is near to the current study. Mahmud et $\mathrm{al}^{11}$, in Rawalpindi noted $38 \% \mathrm{H}$.pylori infection which is more closer to present results. Ali mohammadi et $\mathrm{al}^{12}$ observed $58 \% \mathrm{H}$.pylori in children with RAP while Nadeem and coworkers ${ }^{17}$ noted $62 \%$ H.pylori infection which is again quite similar to the current work. 


\section{CONCLUSION}

Frequency of $\mathrm{H}$.pylori was high in children with RAP. Helicobacter pylori was significantly associated with male gender, younger age, poor socioeconomic status, source of drinking water and disease duration.

Copyright@ 10 May, 2019.

\section{REFERENCES}

1. Okuda $\mathrm{M}^{1}$, Osaki $\mathrm{T}$, Lin $\mathrm{Y}$, Yonezawa $\mathrm{H}$, Maekawa $\mathrm{K}$, Kamiya $\mathrm{S}$, et al. Low prevalence and incidence of Helicobacter pylori infection in children: A population-based study in Japan. Helicobacter. 2015 Apr; 20(2):133-8.

2. Wang $\mathrm{YK}^{1}$, Kuo $\mathrm{FC}^{1}$, Liu $\mathrm{CJ}^{1}$, Wu $\mathrm{MC}^{1}$, Shih $\mathrm{HY}^{1}$, Wang $\mathrm{SS}^{1}$, et al. Diagnosis of Helicobacter pylori infection: Current options and developments. World J Gastroenterol. 2015 Oct 28; 21(40):11221-35.

3. Shu $\mathrm{X}^{1}$, Ping $\mathrm{M}^{2}$, Yin $\mathrm{G}^{3}$, Jiang $\mathrm{M}^{1}$. Investigation of Helicobacterpylori infection among symptomatic children in Hangzhou from 2007 to 2014: A retrospective study with 12,796 cases. Peer J. 2017 Jan 31; 5:e2937. doi: 10.7717/peerj.2937. eCollection 2017.

4. Elhag WI, Omer Ali LE. Frequency of H. pylori antibodies among patients with gastrointestinal symptoms attending khartoum teaching hospitalSudan. SOJ Microbiol Infect Dis. 2014; 2(1):5.DOI: http://dx.doi.org/10.15226/sojmid.2014.00109.

5. Gisbert JP, Calvet X. Update on non-bismuth quadruple therapy for eradication of Helicobacter pylori. ClinExpGastroenterol. 2012; 5:23-34.

6. Abu-Zekry MA, ES-Hashem M, Ali AA, Mohammed IS. Frequency of Helicobacter pylori infection among Egyptian children presenting with gastrointestinal manifestations. J Egypt Public Health Assoc. 2013; 88(2):74-8.
7. Macarthur C, Saunders N, Feldman W. Helicobacter pylori, gastroduodenal disease, and recurrent abdominal pain in children. JAMA. 1995; 273:729-34.

8. Joint ESPGHAN/NASPGHAN guidelines for the management of helicobacter pylori in children and adolescents. Journal of Pediatric Gastroenterology and Nutrition 2017; 64(6).

9. Rajindrajith S, Devanarayana NM, de Silva HJ. Helicobacter pyloriinfection in children. Saudi J Gastroenterol. 2009 Apr; 15(2):86-94.

10. Hafeez A, Ali S, Hassan M. Recurrent abdominal pain and helicobacter pylori infection in children. $J$ Pak Med Assoc. 1999; 49(5):112-4.

11. Mahmud S, Shah SAH, Ali S. Frequency of Helicobacter pylori infection in children with recurrent with abdominal pain. Pak Armed Forces Med J. 2015; 65(3):358-62.

12. Alimohammadi H, Fouladi N, Salehzadeh F, Alipour SA, Javadi MS. Childhood recurrent abdominal pain and Helicobacter pylori infection, Islamic Republic of Iran. East Mediterr Health J. 2017 Feb 1; 22(12):860-64.

13. Mohsen AA, Manji AJ, Hashim J, Obeid RM. The significance of Helicobacter pylori Infection as a cause of recurrent abdominal pain in children. Current Pediatric Research 2018; 22(1):82-7.

14. Younas $M$, Shah S, Talat A. Frequency of giardia lamblia infection in children with recurrent abdominal pain. J Pak Med Assoc. 2008; 58(4):171-74.

15. Zeyrek D, Zeyrek F, Cakmak A, Cekin A. Association of Helicobacter pylori and Giardiasis in children with recurrent abdominal pain. Turkiye Parazitologi Dergisi. 2008; 32(1):4-7.

16. Telmesani AMA. Helicobacter Pylori: Prevalence and relationship with abdominal pain in school children in Makkah city, western Saudi Arabia. Saudi J Gastroenterol. 2009; 15(2):100-3.

17. Nadeem MT, Abbas M, Hassan T, Masood S. Recurrent abdominal pain; the frequency of $\mathrm{H}$. pylori infection in children. Professional Med J. 2006; 13(4):563-71. 


\section{AUTHORSHIP AND CONTRIBUTION DECLARATION}

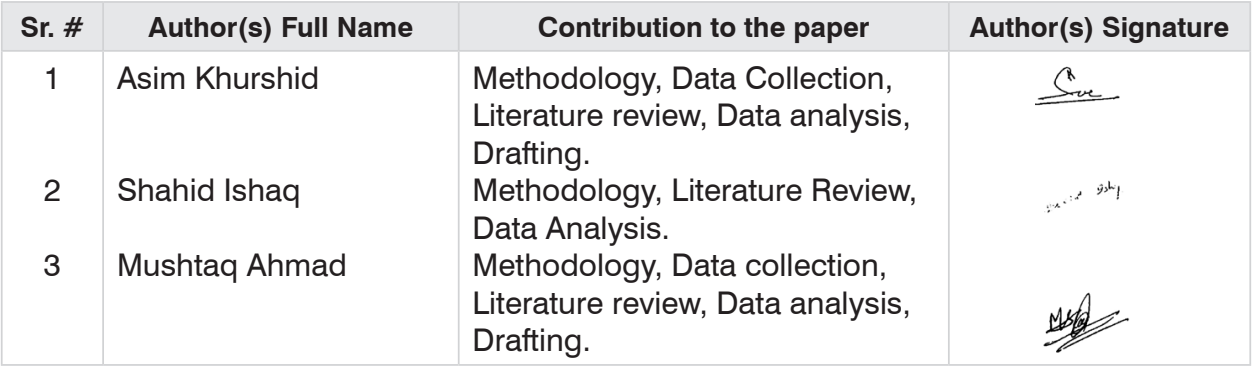

